\title{
Sensitivity and specificity of neuropathy diabetes score, neuropathy symptoms score, diabetic neuropathy score and esthesiometry compared with the gold standards Michigan neuropathy screening instrument (MNSI) and Beck depression inventory (BDI)
}

\author{
Lisiane Stefani Dias*, Otto Henrique Nienov, Maria Cândida Ribeiro Parisi, Helena Schmid
}

From 20th Brazilian Diabetes Society Congress

Porto Alegre, Brazil. 11-18 November 2015

\section{Background}

In a previous study, we observed that the Results of an organized questionnaire to assess the presence of diabetic neuropathy (Diabetic Neuropathy Symptoms-DNS) were associated with the presence of scores of depressive symptoms $(\mathrm{BDI} \geq 10)$.

\section{Objective}

To evaluate how different scores for the presence of symptoms/signs of neuropathy (Neuropathy Diabetes Score-NDS; Neuropathy Symptoms Score-NSS; DNS and esthesiometry) had sensitivity and specificity, compared to the gold standard score of Michigan (MNSI) $(\geq 2,5)$ and the gold standard score of Beck depressive symptoms (BDI).

\section{Materials and methods}

207 patients with Diabetes type 2 were evaluated with MNSI, BDI, NDS, esthesiometry, NSS and DNS.

\section{Results}

Questionnaires used to define the presence of polyneuropathy have a similar sensitivity for the detection of symptoms of depression (70 to $80 \%$ ), while the physical examination for the presence of polyneuropathy (NDS) and esthesiometry has a sensitivity of $\pm 50 \%$ and specificity

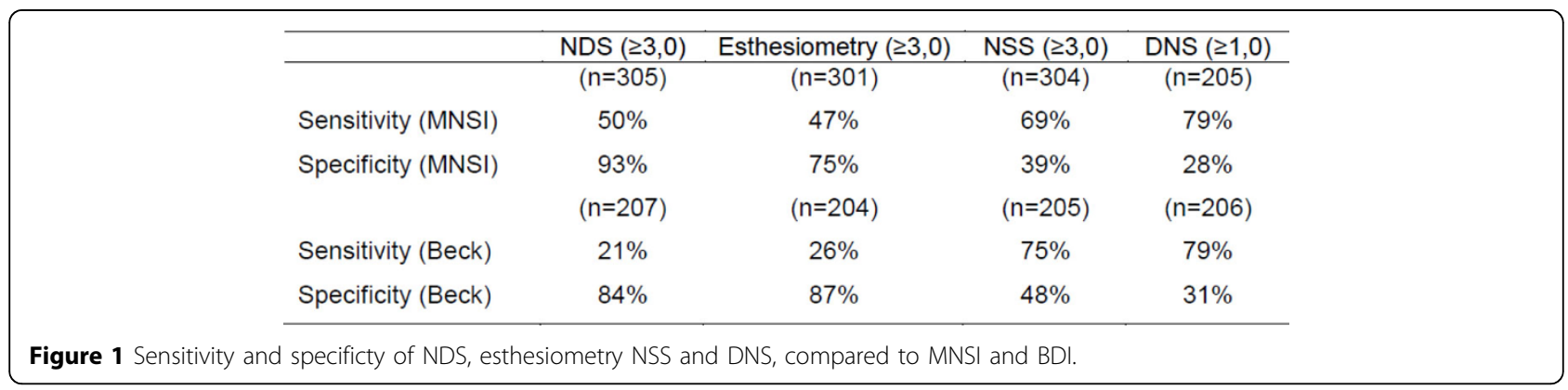

*Correspondence: lisi.sdias@gmail.com

Universidade Federal do Rio Grande Do Sul, Porto Alegre, Brazil

(0) 2015 Dias et al. This is an Open Access article distributed under the terms of the Creative Commons Attribution License (http:// Biomed Central creativecommons.org/licenses/by/4.0), which permits unrestricted use, distribution, and reproduction in any medium, provided the original work is properly cited. The Creative Commons Public Domain Dedication waiver (http://creativecommons.org/publicdomain/ zero/1.0/) applies to the data made available in this article, unless otherwise stated. 
of $\pm 85 \%$ compared to MNSI and a sensitivity of $\pm 23 \%$ and specificity of $\pm 85 \%$ when compared to BDI (Figure 1 ). The symptom questionnaires have sensitivity and specificity of $\pm 75 \%$ and $\pm 35 \%$, respectively, for both MNSI and BDI.

\section{Conclusions}

We suggest not to use only questionnaires to define the presence of neuropathy in diabetic patients-in daily practice, physical examination (MNSI or NDS) must be used.

Published: 11 November 2015

doi:10.1186/1758-5996-7-S1-A199

Cite this article as: Dias et al:: Sensitivity and specificity of neuropathy diabetes score, neuropathy symptoms score, diabetic neuropathy score and esthesiometry compared with the gold standards Michigan neuropathy screening instrument (MNSI) and Beck depression inventory (BDI). Diabetology \& Metabolic Syndrome 2015 7(Suppl 1):A199.

Submit your next manuscript to BioMed Central and take full advantage of:

- Convenient online submission

- Thorough peer review

- No space constraints or color figure charges

- Immediate publication on acceptance

- Inclusion in PubMed, CAS, Scopus and Google Scholar

- Research which is freely available for redistribution

Submit your manuscript at www.biomedcentral.com/submit 